\title{
Tratamiento Endodóntico no Instrumentado en dientes deciduos
}

Perona- $G^{1}$

Mungi-S ${ }^{2}$

\section{Resumen}

Teniendo en cuenta la complejidad del tratamiento pulpar en una pieza decidua y diversos factores que determinan el éxito clínico como son la anatomía de una pieza decidua, el proceso de reabsorción ya sea de origen fisiológico o por una infección odontogénica, la conducta del paciente, la técnica empleada y la pericia del operador; es de suma importancia que en la práctica odontopediátrica se tenga en cuenta ciertos procedimientos que aseguren la presencia del diente en boca hasta su exfoliación fisiológica, es de esta manera que la Técnica de Endodoncia no Instrumentadas en dientes deciduos es un tema muy importante a tener presente en cuanto a terapia pulpar se refiere. Las pulpectomías no instrumentadas (NIET); termino mal empleado para este procedimiento, ya que la técnica no consiste en realizar una pulpectomía propiamente dicha; en su lugar emplean diversas pastas que tienen por objetivo la desinfección de los conductos radiculares mediante el empleo de sustancias bacteriostáticas y bactericidas y de esta manera permitirán la reparación del los tejidos dañados. El propósito de este artículo fue hacer una revisión de la literatura de todo lo concerniente a Terapia Endodóntica no Instrumentada en dentición decidua. En conclusión se puede decir que dadas las características de la dentición temporal, la cual impide una completa manipulación de los conductos radiculares, el éxito de la pulpectomía depende de la reducción o eliminación de las bacterias no solo dentro del conducto sino también en lugares donde la preparación química y mecánica sea difícil de acceder, en la técnica NIET se utiliza una mezcla de antibióticos para esterilizar el conducto radicular en vez de usar la técnica de instrumentación, las pastas obturadoras asumen un papel fundamental para que la reparación de los elementos dentarios se desenvuelva de acuerdo a los patrones biológicos normales.

Palabras clave: terapia, endodóncia, diente deciduo.

Artigo de revisão

\section{Terapia Endodôntica sem Instrumentação na dentição decídua}

\section{Resumo}

Considerando a complexidade do tratamento pulpar de dentes decíduos e os diversos fato- res que determinam seu sucesso clínico, como a sua anatomia, o processo de reabsorção seja fisiológico ou devido à infecção odontogênica, o

\footnotetext{
${ }^{1}$ Docente de Posgrado de la Universidad Científica del Sur, Lima-Perú

${ }^{2}$ Residente de 2 do año Especialidad Odontopediatría, UCSUR
} 
comportamento infantil, a técnica utilizada e a habilidade do operador, é de suma importância que a prática odontopediátrica considere certos procedimentos para a manutenção bucal do dente decíduo até sua esfoliação fisiológica. Dessa forma é muito importante considerar a Técnica Endodôntica sem Instrumentação em dentes decíduos quando a terapia pulpar é necessária. A denominação Pulpectomias sem Instrumentação (NIET) é empregada inadequadamente para esse procedimento já que a técnica não consiste em realizar uma pulpectomia propriamente dita, em vez disso, se empregam diversas pastas que têm como objetivo desinfetar os condutos radiculares mediante o emprego de substâncias bacteriostáticas e bactericidas e, desta maneira, permitir a reparação dos tecidos lesados. O objetivo deste artigo foi fazer uma revisão da literatura en- volvendo todos os aspectos relativos à Terapia Endodôntica sem Instrumentação na dentição decídua. Pode se concluir que devido às características da dentição decídua, a qual impede uma completa manipulação dos condutos radiculares, o êxito da pulpectomia depende da redução ou eliminação bacteriana não somente dentro do conduto como também nos sítios onde o preparo químico e mecânico dificilmente alcança. Na técnica NIET, em vez da técnica de instrumentação, se utiliza uma combinação de antibióticos para esterilizar o conduto radicular. As pastas obturadoras assumem um papel fundamental para que a reparação dos elementos dentários ocorra de acordo com os padrões biológicos normais.

Palavras chave: Terapêutica, Endodontia, Dente Decíduo.

Review article

\section{Non Instrumental Endodontic Treatment in Primary Teeth}

\section{Abstract}

Because of the complexity of pulp treatment in primary teeth and various factors that determine the clinical success such as: the anatomy of primary teeth, the resorption process either physiological causes or odontogenic infection, the patient's behavior, the technique used and the skill of the operator. It's important in pediatric dental practice certain procedures to ensure the presence of tooth in the mouth until the physiological exfoliation, it is very useful to keep in mind Non Instrumental Endodontic Treatment (NIET) when pulp therapy is indicated. The Non Instrumented pulpectomy bad word said; for this procedure, because of the technique does not consist in making a con- ventional pulpectomy; instead it has various compounds that aid to sterilize root canals by using bacteriostatic and bactericides agents and thus will allow repair damaged tissues. The purpose of this paper was to review the literature concerning Non Instrumented Endodontic Therapy in primary teeth. In conclusion we can report that given the characteristics of primary teeth, which avoid a complete manipulation of root canals, successful pulpectomy depends on the reduction or elimination of bacteria not only in root canals, also in places where the chemical and mechanical preparation is difficult to access. That's why in Non Instrumental Endodontic Therapy a mixture of antibiotics is used to sterilize the root canal instead of using the technique of instru- 
mentation, sealing materials play a central role in repair the dental tissue according to normal biological patterns.

Key words: therapy, endodontic, primary teeth.

\section{Introducción}

La dentición temporal tiene una importancia fundamental tanto por su estética, fonación, masticación y por el bienestar psicosocial del infante; además de mantener el espacio necesario para la erupción favorable de los dientes permanentes. ${ }^{1}$ De esta manera todos nuestros recursos deben ser utilizados para evitar la pérdida prematura de los dientes temporales. ${ }^{2}$ Un gran número de casos de caries profundas, generalmente, requieren la necesidad de algún tipo de terapia pulpar, siendo el principal objetivo mantener la integridad y salud del órgano dentario, así como también de sus tejidos de soporte. ${ }^{3} \mathrm{La}$ terapia pulpar requiere de un examen clínico y radiográfico periódico de los órganos tratados así como de sus estructuras de soporte. ${ }^{4}$ La pulpectomía convencional tiene como pasos la limpieza, irrigación y obturación de canales con un material de relleno. ${ }^{5}$

Sin embargo, la conformación peculiar y topografía de los conductos radiculares de los dientes deciduos con curvaturas y una gran cantidad de conductos accesorios dificultan el acceso y la instrumentación del diente. ${ }^{6}$ Además del aspecto anatómico, el proceso de reabsorción de la raíz en dientes deciduos es irregular y no siempre se detecta radiográficamente. ${ }^{7}$ Este hecho significa que hay dificultad de establecer un límite con las limas y para el llenado del canal, con la posibilidad de lesionar el periodonto y lograr daño en el germen del diente permanente. ${ }^{5}$

\section{Pulpa dental}

Es un tejido conjuntivo laxo de origen mesenquimatoso que se encuentra encerrado en el interior de la cámara pulpar y de los conductos radiculares. ${ }^{2}$ Constituye junto a la dentina una unidad denominada complejo pulpo dentinario. ${ }^{2,4}$ La pulpa dental contiene alto contenido de células (fibroblastos, macrófagos, linfocitos) fibras colágenas y reticulares, sustancia fundamental amorfa, liquido tisular, vasos sanguíneos, linfáticos y nervios. ${ }^{3}$

El tejido pulpar cumple cuatro funciones básicas para el diente, la primera y la más importante es la de la formación de dentina, función sensitiva, a través de sus fibras nerviosas; función de nutrición, a través de su rica microvasculatura y de función de protección, mediante la formación de dentina reparativa o terciaria. ${ }^{2}$

\section{Factores etiológicos de la enfermedad pulpar y periapical}

Los estímulos capaces de producir inflamación y necrosis de la pulpa, así como sus complicaciones periapicales son múltiples en el Cuadro 1 se describen los principales factores etiológicos. 3,5

\section{Clasificación de las enfermedades pulpares}

Pulpitis Reversible: Estado de inflamación transitoria. Se produce un dolor agudo pero temporal debido a la acción de diversos irritantes externos tales como caries poco profundas. Si estos estímulos son tratados y diagnosticados a tiempo puede recuperarse la vitalidad pulpar. ${ }^{5}$

Pulpitis Irreversible: Es la inflamación de la pulpa sin capacidad de recuperación, a pesar de 
Cuadro 1. Factores etiológicos enfermedad pulpar.

\begin{tabular}{|c|c|}
\hline \multicolumn{2}{|c|}{ FACTORES ETIOLÓGICOS DE LA ENFERMEDAD PULPAR } \\
\hline FACTORES BACTERIANOS & $\begin{array}{l}\text { Las bacterias y sus productos representan las } \\
\text { causas más frecuentes de enfermedad endodón- } \\
\text { tica. La respuesta pulpar a la caries es inflama- } \\
\text { toria debido a que los túbulos dentinarios son } \\
\text { permeables, pueden llegar a la pulpa a través } \\
\text { de varias vías como: caries dental, periodonto, } \\
\text { traumatismos, filtración marginal, anomalías de } \\
\text { desarrollo y circulación sanguínea. }{ }^{5}\end{array}$ \\
\hline FACTORES TRAUMÁTICOS & $\begin{array}{l}\text { La respuesta a traumatismos tales como golpes } \\
\text { o accidentes puede ser variable, algunas pul- } \\
\text { pas aparentemente curan sin efectos adversos; } \\
\text { mientras otras experimentan una necrosis. Los } \\
\text { traumatismos que producen una exposición } \\
\text { pulpar o dentinaria son causa de inflamación } \\
\text { por posibilitar la llegada de bacterias a la pulpa; } \\
\text { cuando el traumatismo no ocasiona una comu- } \\
\text { nicación de la pulpa con la cavidad bucal, pero } \\
\text { sí la necrosis pulpar, las bacterias pueden llegar } \\
\text { por anacoresis. }\end{array}$ \\
\hline FACTORES IATROGÉNICOS & $\begin{array}{c}\text { Entran en esta categoría aquellos procedimientos } \\
\text { restauradores que generen calor y desecación } \\
\text { de túbulos dentinarios, productos y sustancias } \\
\text { químicas que puedan provocar una irritación } \\
\text { pulpar, raspado periodontal que seccione una } \\
\text { arteriola que transcurra por un conducto lateral } \\
\text { y por movimientos ortodónticos demasiado } \\
\text { bruscos. }{ }^{5}\end{array}$ \\
\hline FACTORES IDIOPÁTICOS & $\begin{array}{l}\text { Podemos señalar aquí a la resorción interna o } \\
\text { factores desconocidos que puedan causar enfer- } \\
\text { medad pulpar y/o periapical. }{ }^{5}\end{array}$ \\
\hline
\end{tabular}

que cesen los estímulos externos causantes del proceso inflamatorio. ${ }^{6}$

Necrosis Pulpar: Es la muerte pulpar donde terminan todos los procesos metabólicos de este órgano, con pérdida de su estructura como consecuencia final de un proceso patológico en el cual la pulpa no pude reintegrarse a la normalidad por no tener capacidad de reacción. ${ }^{5}$ 


\section{Pulpectomía convencional}

Procedimiento que consiste en la eliminación mecánica del tejido pulpar que se encuentra infectado o necrótico debido a caries o trauma; indicado en dientes temporales con pulpitis irreversible o necrosis, también cuando en una pulpotomía, la pulpa radicular exhiba signos clínicos de pulpitis irreversible. ${ }^{4}$

La desventaja de este procedimiento es su complejidad para llevarse a cabo, pues implica un número mayor de pasos operatorios, el uso de aislamiento absoluto y de instrumentación, agregando a esto la poca colaboración del niño que hace a esta técnica un procedimiento complejo. ${ }^{8}$ Dadas las características de la dentición temporal, la cual impide una completa manipulación de los conductos radiculares, el éxito de la pulpectomía depende de la reducción o eliminación de las bacterias no solo dentro del conducto sino también en lugares donde la preparación química y mecánica sea difícil de accesar. $^{9}$ Considerando las limitaciones para la instrumentación de los conductos de los dientes temporales, el uso de pastas de obturación que presentan capacidad antimicrobiana representa uno de los aspectos más importantes en el éxito de la pulpectomia. ${ }^{10}$

\section{Pulpectomía no instrumentada}

Un grupo de investigadores japoneses desarrolló el concepto de la terapia endodóntica no instrumentada (NIET), empleando una mezcla de fármacos antibacterianos para la desinfección de la pulpa. ${ }^{11,13}$ Ellos también apoyan la hipótesis que si hay una esterilización de la lesión podrá producirse la reparación de los tejidos, de ahí nace el concepto denominado esterilización de la lesión y reparación de los tejidos (LSTR). ${ }^{12}$

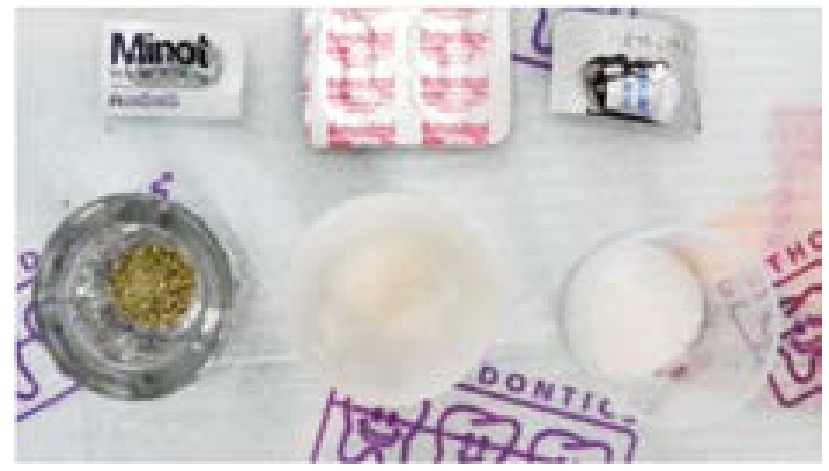

Figura 1. Antibióticos utilizados para la pasta 3Mix: minociclina, ciprofloxaxino y metronidazol.

La técnica consiste en la colocación de una pasta a base de componentes antimicrobianos unidos a un vehículo que se colocarán en la entrada de cada canal de la raíz. ${ }^{14}$

Los medicamentos más usados para esta terapia son: tetraciclinas, metronidazol, ciprofloxacino; y como vehículos el macrogol, propilenglicol y eugenato ${ }^{15}$; en la Figura 1 podemos apreciar los medicamentos utilizados para la pasta 3Mix. Las pastas 3Mix y CTZ son las más conocidas para esta técnica. ${ }^{14}$

Las dificultades para la esterilización de la raíz infectada usando protocolos disponibles ha estimulado la investigación de nuevas técnicas dirigida a lograr la muerte completa de los microorganismos en los conductos accesorios. ${ }^{11}$

En el Cuadro 2 se indica las ventajas, desventajas e indicaciones de la pulpectomía no instrumentada. ${ }^{17,18}$

\section{Técnica endodóntica no instrumentada ${ }^{19}$}

1. Administración del anestésico local.

2. Aislamiento absoluto con dique de goma.

3. Eliminación del techo de la cámara pulpar. 
Cuadro 2. Ventajas, desventajas e indicaciones para pulpectomias no instrumentadas.

\begin{tabular}{|c|c|c|}
\hline VENTAJAS & DESVENTAJAS & INDICACIONES \\
\hline $\begin{array}{c}\text { Elimina bacterias aisladas } \\
\text { de los conductos radiculares } \\
\text { infectados }\end{array}$ & Requiere más investigación & $\begin{array}{c}\text { Niños no colaboradores que } \\
\text { tengan varios tratamientos } \\
\text { pulpares }\end{array}$ \\
\hline $\begin{array}{c}\text { Penetra en los conductos } \\
\text { accesorios }\end{array}$ & $\begin{array}{c}\text { Efectos secundarios a los } \\
\text { antibióticos empleados }\end{array}$ & $\begin{array}{c}\text { Dientes temporales con } \\
\text { raices reabsorbidas que por } \\
\text { motivo especifico deban } \\
\text { permanecer en boca }\end{array}$ \\
\hline Éxito clínico & Reacciones alérgicas & $\begin{array}{c}\text { Tratamiento de la pulpi- } \\
\text { tis irreversible en mola- } \\
\text { res permanentes jóvenes } \\
\text { vitales(ápice por completar) }\end{array}$ \\
\hline & $\begin{array}{c}\text { Puede aparecer cepas resis- } \\
\text { tentes a antibióticos bacte- } \\
\text { rianos }\end{array}$ & $\begin{array}{c}\text { Tratamiento de pulpitis } \\
\text { irreversible en molares tem- } \\
\text { porales vitales, incluso en } \\
\text { presencia de un absceso }\end{array}$ \\
\hline & & Necrosis pulpar \\
\hline
\end{tabular}

4. Secado de la cavidad con torundas de algodón estéril.

5. Irrigación de cámara pulpar con solución de Dakin (hipoclorito de sodio al 0.5\%) y aspiración con cánula de alta succión.

6. Irrigación de conductos con solución de Dakin (hipoclorito de sodio al $0.5 \%$ ) y aspiración con cánula de alta succión (opcional).

7. Secado de la cavidad con torundas de algodón estéril.

8. Manipulación de la pasta y colocación de la misma sobre el piso de la cámara pulpar.

9. Colocación de cemento de obturación temporal.
En la Figura 2 podemos observar la técnica descrita.

\section{Materiales usados}

Las pastas obturadoras asumen un papel fundamental para que la reparación de los elementos dentarios se desenvuelva de acuerdo a los patrones biológicos normales. ${ }^{10}$

Por tanto se torna fundamental la utilización de un medicamento que imposibilite la sobrevivencia de microorganismos ${ }^{11}$. Los criterios necesarios para el material obturador ideal en dientes deciduos son los siguientes: ${ }^{10}$

- Presentar un grado de reabsorción semejante al de la raíz del diente. 

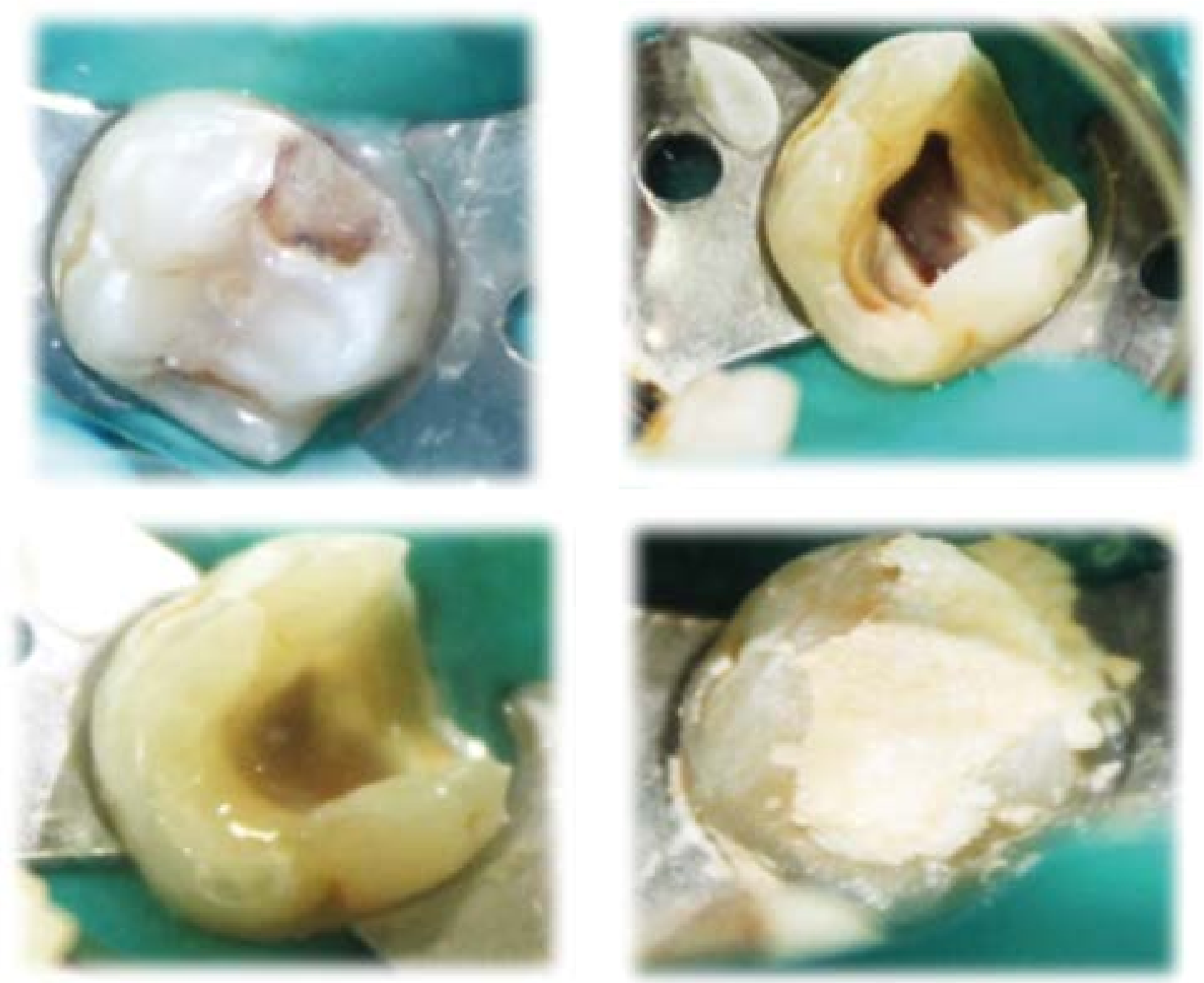

Figura 2. Secuencia de Técnica Endodóntica no Instrumentada.

- Ser inofensivo a los tejidos periapicales y al gérmen del diente permanente.

- Ser reabsorbible en casos de extravasación de material.

- Poseer propiedades antisépticas.

- Ser aplicado con facilidad y poseer buena adhesión a las paredes de los conductos.

- Poder ser removido fácilmente.

- Ser radiopaco y no pigmentar el diente.
La Pasta 3Mix - MP: Ha sido desarrollada durante los últimos años como una manera novedosa de tratar las piezas deciduas necróticas indicadas para tratamientos de pulpectomías, facilitando su procedimiento y mejorando los resultados clínicos ${ }^{20}$.

En los últimos años la Facultad de Odontología de la Universidad de Nigata, en Japón ha desarrollado el concepto de "Esterilización de Lesiones y Reparación Tisular", o también denominada terapia LSTR, la cual emplea una mezcla de antibióticos para la desinfección de infecciones 
orales producidas por piezas dentarias y la cual se basa en el empleo de esta pasta; la misma que tiene la capacidad de difundirse a través de los conductos radiculares hasta la zona periapical y ejercer su acción bactericida in situ. ${ }^{18}$

Los estudios realizados han demostrado que 3Mix es capaz de eliminar las bacterias de tejidos dentales infectados de dientes deciduos y permanentes, constituyéndose como una excelente alternativa para piezas deciduas indicadas para tratamientos de pulpectomía. ${ }^{19}$

Otros estudios han demostrado su eficacia en tratamientos endodónticos en piezas permanentes como por ejemplo como medicación intraconducto en casos de re-tratamientos, infecciones recurrentes por Enterococcus faecalis o en casos de lesiones periapicales crónicas producto de perforaciones radiculares. Sin embargo son estudios preliminares aunque no por ello menos importantes. ${ }^{21}$

La pasta 3Mix-Mp consta de dos partes: polvo y líquido. El polvo está formado por:

Metronidazol, Ciprofloxacina y Minociclina en una proporción de 1:1:1 (Figura 1); y la parte liquida está formado por una combinación de Macrogol y Propylenglicol, también en proporción 1:1 (Figura 3); estos últimos actúan como vehículos transportadores de los antibióticos. ${ }^{18}$

Metronidazol: Familia de los los nitromidazoles es un antibiótico que tiene actividad in vitro contra una amplia variedad de parásitos protozoarios y anaerobios, Posee actividad antibacteriana contra todos los cocos anaerobios y bacilos gramnegativos anaerobios, incluidas especies de bacteroides y bacilos, presenta efecto bactericida al inhibir la síntesis de ácidos nucleicos en los microorganismos obligadamente anaerobios, independientemente de la fase de crecimiento bacteriano. ${ }^{22}$
Ciprofloxacino: Es una quinolona de segunda generación, perteneciente al grupo de las Fluoroquinolonas. ${ }^{23}$ Estos antimicrobianos ejercen un efecto bactericida por inhibición selectiva de la síntesis de $\mathrm{ADN}$ en la bacteria: inhibiendo a la ADN - girasa, una enzima necesaria para la replicación del ADN y algunos aspectos de la trascripción, recombinación y transposición, inhibiendo la relajación del ADN súper duplicado y promoviendo la ruptura del ADN doble cadena. ${ }^{24}$

Minociclina: Las tetraciclinas son antibióticos bacteriostáticos de amplio espectro; actúan contra una amplia gama de bacterias grampositivas y gramnegativas anaerobias y aerobias. Son también eficaces contra algunos microorganismos resistentes a antimicrobianos activos contra la pared bacteriana. ${ }^{24}$ Las Tetraciclinas son activas contra muchos microorganismos anaerobios y facultativos; su actividad tiene particular importancia contra Actinomyces. ${ }^{23}$

Propylenglicol: Se define como un líquido incoloro, viscoso e higroscópico. Las propiedades físicas del Propylenglicol son semejantes a la del Etilenglicol, pero mucho menos toxico. ${ }^{25}$ Por esta razón esta sustancia se utiliza como solvente en fármacos, cosméticos, lociones y ungüentos; en productos alimenticios; como plastificador; en presentaciones anticongelantes; en el intercambio calórico y en líquidos hidráulicos. ${ }^{26}$

Macrogol: Se utiliza como vehículo en farmacología dermatológica. Los polietilenglicoles o Macrogoles son productos de policondensación de óxido de etileno y agua; su consistencia varía conforme a la longitud de la cadena: a mayor longitud de cadena la consistencia será más dura $^{26}$ Es altamente soluble en agua y en solución salina acuosa, así como en soluciones ácidas o alcalinas. ${ }^{25}$ Es prácticamente insoluble en 
alcohol, éter y en aceites grasos y aceites minerales. Su solución acuosa muestra excelente lubricación. Se descompone en altas temperaturas y no deja residuos. ${ }^{27}$

Preparación de la pasta 3Mix - Mp: La pasta 3Mix - Mp tiene como principal indicación ser preparada el mismo día del tratamiento. ${ }^{27} \mathrm{La}$ preparación de la pasta $3 \mathrm{Mix}$ - Mp debe ser hecha preferentemente por el operador para estar seguro de la consistencia ideal y de las proporciones correctas (Figura 3). La preparación de 3Mix- MP puede ser usada durante el día, sin embargo, la cantidad de 3Mix-MP sobrante deberá ser eliminada al final de las horas de trabajo. Para esto se necesita: Tres recipientes con las drogas pulverizadas. ${ }^{28}$

1. Usando una espátula, tomar el Metronidazol en polvo sobre la platina. Secar y limpiar la espátula para evitar contaminación del Metronidazol con la siguiente droga en polvo.

2. Usando una espátula limpia y seca, colocar la misma cantidad de Minociclina en polvo sobre la superficie de mezcla. Limpiar y secar la espátula para evitar la contaminación de la Ciprofloxacina.

3. Realizar la misma acción con la Ciprofloxacina y usando exactamente la misma cantidad.

4. Mezclar estos tres componentes (3Mix); Metronidazol: Minociclina: Ciprofloxacina = $1: 1: 1 .^{27,28}$

5. En otra área de la platina, tomar una parte de PropyleneGlicol (P) y el mismo volumen de Macrogol (M). Mezclar bien hasta formar un solo compuesto líquido (MP) de textura similar a la crema batida $\mathrm{M}: \mathrm{P}=1: 1{ }^{27}$

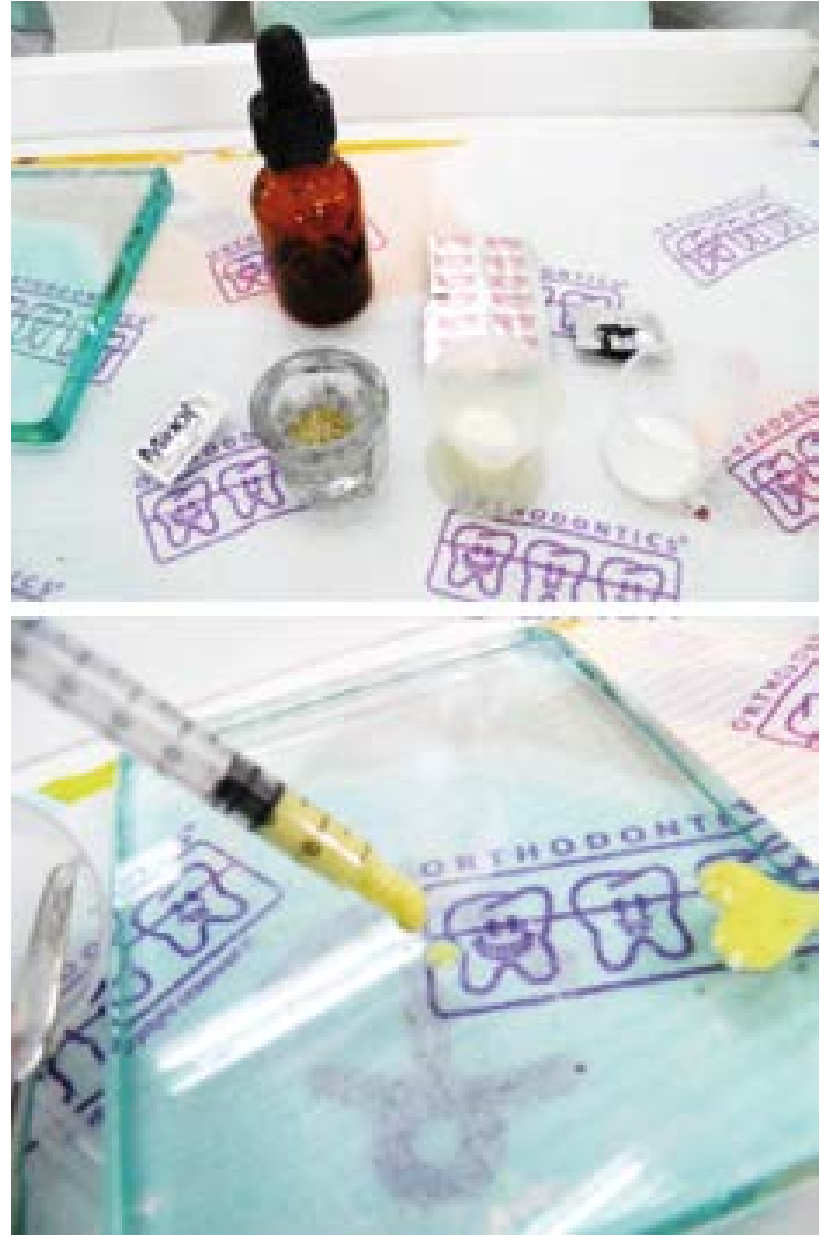

Figura 3. Preparación de la pasta Trimix: Macrogol-propilenglicol/minociclina, ciprofloxacino y metronidazol.

6. Finalmente, para la preparación Standard de 3Mix-Mp, mezclar una parte de MP contra 7 partes de 3Mix; es decir 3Mix: $\mathrm{MP}=7: 1{ }^{28}$

Pasta CTZ: Descrita por Sollier y Cappiello ${ }^{29}$ en 1959 esta pasta está compuesta por:

- Cloranfenicol 500mg.

- Tetraciclina 500mg.

- Óxido de zinc 1000mg.

- Eugenol (1 gota).

Cloranfenicol: Sustancia obtenida a partir del Streptomyces Venezuelae, antibiótico de amplio 
espectro, bacteriostático eficaz contra grampositivos, gramnegativos incluyendo hongos como: Candida Albicans, causa Anemia aplásica por tratamientos largos, petequias, sangrado de mucosa oral, ulceras orales. ${ }^{21}$

Tetraciclina: Antibiótico de amplio espectro actúa contra cocos y bacilos grampositivos, gramnegativos, Cándidas, E coli, Pseudomonas puede causar cambio de color o hipoplasia del esmalte si es administrada en el periodo de calcificación dentaria. ${ }^{1}$

Óxido de Zinc - Eugenol: Ha sido el material de elección por muchos años, es empleado por el $94 \%$ de las universidades de odontología ${ }^{19} \mathrm{El}$ rango de éxito clínico utilizando este material varía del 68,7\% al 86,1\%. ${ }^{18}$ Aunque este agente ha demostrado en varios estudios su efecto antibacteriano contra cultivos puros se ha visto que combinado con formocresol incrementa su efecto antibacteriano. ${ }^{19}$ Estudios In vitro han demostrado que a pesar de su alto efecto antibacteriano el ZOE por sí solo no podía inhibir a Escherichia coli, S. aureus o Streptococcus viridans. ${ }^{18}$

Pasta Pulpotec ${ }^{\circledR}$ : Pasta radiopaca no reabsorbible, indicada para el tratamiento de la pulpitis irreversible en molares vitales tanto permanentes y deciduos. ${ }^{30}$

Composición: Polvo: Polioximetileno, yodoformo.

Líquido: Dexametasona, formaldehído, fenol, guayacol.

Tratamiento aséptico, induce la cicatrización del muñón pulpar. El tratamiento de pulpitis con Pulpotec® es más rápido que la pulpectomía., Evita numerosos fracasos que se han observado con el llamada pulpectomía. La eficacia se fundamenta en un archivo radiográfico de 300

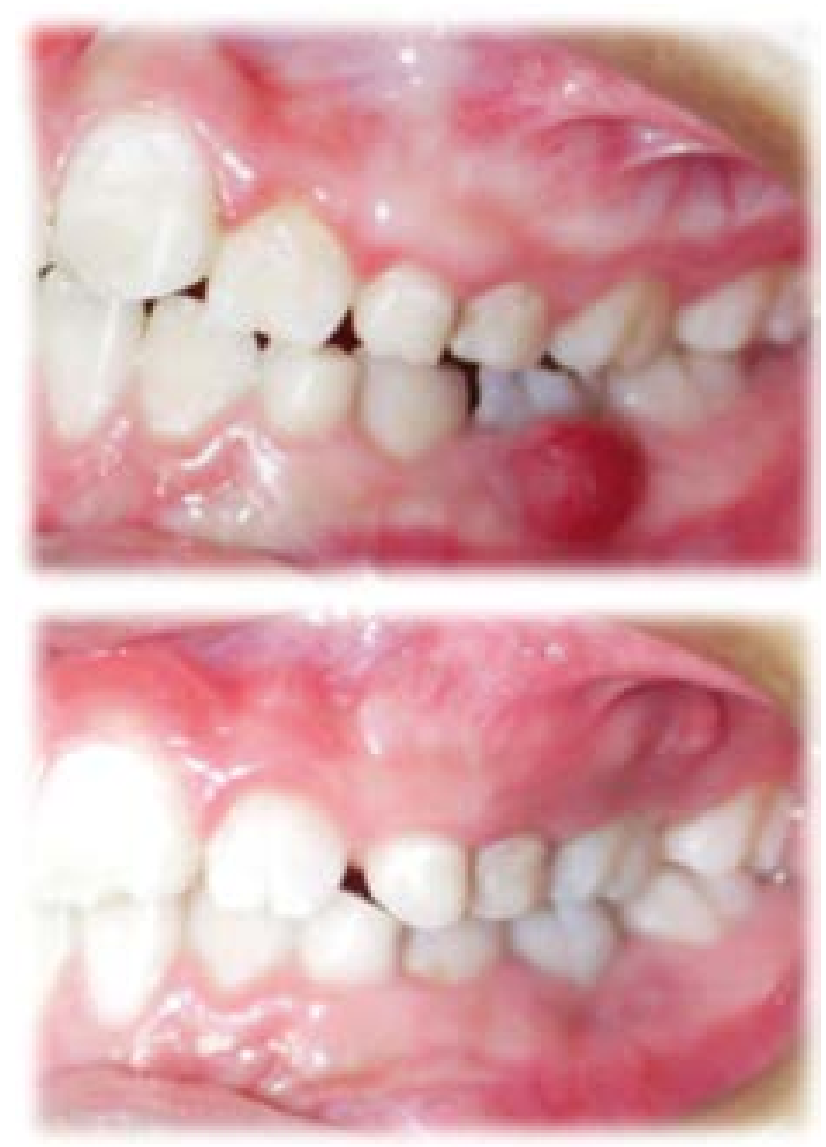

Figura 4. Antes y después de pza. 75 tratada con Pasta Trimix.

pulpotomías realizadas con Pulpotec ${ }^{\circledR}$ y supervisadas por períodos de 3 a 13 años. ${ }^{31}$

\section{Conclusiones}

La pulpa dental es un tejido conjuntivo laxo de origen mesenquimatoso que se encuentra encerrado en el interior de la cámara pulpar y de los conductos radiculares.

El tejido pulpar cumple cuatro funciones básicas para el diente: formación de dentina, función sensitiva, función de nutrición y función de protección.

Factores que conllevan a una enfermedad pulpar son: bacterianos, traumáticos, iatrogénicos e idiopáticos. 
La patología pulpar se clasifica en: Pulpitis reversible, Pulpitis irreversible y Necrosis pulpar.

Dadas las características de la dentición temporal, la cual impide una completa manipulación de los conductos radiculares, el éxito de la pulpectomía depende de la reducción o eliminación de las bacterias no solo dentro del conducto sino también en lugares donde la preparación química y mecánica sea difícil de acceder.

En la técnica NIET se utiliza una mezcla de antibióticos para esterilizar el conducto radicular en vez de usar la técnica de instrumentación.
Las pastas obturadoras asumen un papel fundamental para que la reparación de los elementos dentarios se desenvuelva de acuerdo a los patrones biológicos normales.

La técnica NIET está recomendada para pacientes no colaboradores y/o reabsorción radicular y la pieza dental tenga que mantenerse en boca.

La pasta 3Mix, CTZ Y Pulpotec son usadas para la técnica endodóntica no instrumentada.

Los estudios hasta el momento han dado mejores resultados con la pasta $3 \mathrm{mix}$.

\section{Referencias}

1. Sato T, Hoshino E, Uematsu H, Noda T. In vitro antimicrobial susceptibility to combinations of drugs of bacteria from carious and endodontic lesions of human deciduous teeth. Oral Microbiology \& Immunology 1993; 8(3):172-76.

2. Quispe A. Evaluación del efecto antibacteriano de la combinación de drogas 3Mix en bacterias anaerobias prevalentes en necrosis pulpar. [Tesis para obtener el Título de Cirujano Dentista] 2007. UNMSM.

3. Sato T. Sterilization of infected root-canal dentine by topical application of a mixture of ciprofloxacin, metronidazol and minocycline in situ. J Int Endod. 1996; 29(2):118 -124.

4. Hoshino E. In vitro antimicrobial susceptibility o bacteria taken from infected root dentine to a mixture of ciprofloxacin, metronidazole and minicycline. J. Int Endod. 1996; 29(2): 125 -130.

5. Ando N. Hoshino K. Predominant anaerobes invading the deep layer of root canal dentine. J Int Endod. 1990; $23: 20-7$.

6. González-Núñez D. Técnica de endodoncia no instrumentada mediante el uso de la pasta CTZ. Rev. Estomat. 2010; 18(2):27-32.

7. Tachau Wen - Shiun. In vitro inhibition of bacteria from root canals of primary teeth by various dental materials. Pediatric dentistry 1995; 17(5): 55-60.

8. Bengston A, Bengston N. Efeito da instrumentação endodôntica em molares decíduos. Rev Assoc Paul Cir Dent. 1993; 47(5):1149-54.

9. Faraco Jr I, Percinoto C. Avaliação de duas técnicas de pulpectomia em dentes decíduos. Rev Assoc Paul Cir Dent 1998; 52(5):400-4.

10. Young G. The principles of techniques for cleaning root canal. Journal Australian Dental. 2007; 52:(1): 52-63.

11. Iwaya S, Ikawa M, Kubota M. Revascularization of an immature permanent tooth with apical periodontitis and sinus tract. Dental Traumatology 2011; 17. 185-7

12. Takushige T, Cruz E, Moral A, Hoshino E. Endodontic treatment of primary teeth using a combination of antibacterial drugs. J Int Endod 2009; 27: 132-138

13. Rabinowitch B: Pulp management in primary teeth. Oral Surg Oral Med Oral Pathol 1953; 6:542-50, 671-6.

14. American Academy of Pediatric Dentistry. Guideline on Pulp Therapy for Primary and Immature Permanent Teeth. 2009.

15. Hoshino E. Sterilization of carious lesions by drugs. J of the Japanese Association for Dental Science 1990; 9:32-37. 
16. Ozalp N, Saroglu I, Sonmez H, Evaluation of various root canal filling materials in primary molar pulpectomies: An in vivo study. Am J Dent 2005; 18:347-50

17. Siriruk N, Panit B, Nattida V. Clinical evaluation of 3Mix and Vitapex as treatment options for pulpally involved primary molars. International Journal of Paediatric Dentistry 2010; 20: 214-221

18. Cruz E. et al. Penetration of Propylene glycol into dentine. International Endodontic Journal 2002;34(4):330-2

19. Hoshino E, Kota k, Sato M, Ando N. Batericidal efficacy of Metronidazol against bacteria of human carious dentin in vivo. Caries Research 1996; 23:78-80

20. Zavistosky J. Dzink J. Onderdonk A. Bartlett J. Quantitative bacteriology of endodontic infections. Oral Surgery. Oral Medicine and Oral Pathology 1988; 49. 171-4.

21. Nivoloni P, Guimaràes L, Pontes C, Barcelos R. Long-term Outcomes of Primary Tooth Pulpectomy With and Without Smear Layer Removal: A Randomized Split-mouth Clinical Trial. Pediatric Dentistry 2011; 33 (4): 316-20

22. Abuquerque I, Marinho J, Vasconcelos P. Utilizacao da pasta CTZ em dente decíduo com necrose pulpar-relato de caso. Odont Clin Cientif Recife 2008; 7:63-55.

23. Carmona D, Trejo P, De León A, Gonzáles D. Técnica de endodoncia no instrumentada mediante el uso de la pasta CTZ. Rev Estomat 2010; 18(2): 27-32.

24. Iwaku M, Hoshino E, Kota K. Lesion sterilization and tissue repair therapy: New pulpal treatment, how to conserve infected pulps. Tokyo, Japan: Nihon-Shika-Horon 1996; 34:12-6

25. Black A, Redmond AOB. Sleen H.I. Oborska IT. Tolerance and safety of ciprolloxacin in paediatric palients. Antimicrob Chemolher 1990; 26: 2529.

26. Sato T, Hoshino E, Umatsu H, Kota K. Iwaku M. Noda T. Bactericidal efflcacy of a mixture of ciprofloxacin. metronidazole. minocycline and rifampicin against bacteria of carious and endodontic lesions of human deeiduous teeth in vitro. Microbial Ecology in Health andDisease 1992; 5: 171-7

27. Abuquerque I, Marinho J, Vasconcelos P. Utilizacao da pasta CTZ em dente decíduo com necrose pulpar-relato de caso. Odont Clin Cientif Recife 2008; 7:63-55.

28. Hoshino E, Iwaku M, Sato M, Ando N, Kota K. Bactericidal efficacy of metronidazole against bacteria of human carious dentin in vivo. Caries Res 1989; 23: 78-80.

29. Marmesse A. Final reports of clinical trials of pulpotec (Translation of the original text). Unpublished article [Acceso: 02/06/2014]. Disponible en: http:/ / www.pulpotec.com

30. http: / / www.pulpotec.com. [Fecha de acceso: 02/06/2014]

31. Al-Salman KA, Al-Rawi BA, Rahawy OS. The Effectiveness of Using Pulpotec ${ }^{\circledR}$ in Treatment of Pulpitis by Pulpotomy of Vital Deciduous Molar and Vital Immature Permanent Molar. Al-Rafidain Dent J. 2012; 12(1): 185-190.

Recibido: 02-04-2014

Aceptado: 23-05-2014

Correspondencia: Sabina Mungi, Universidad Científica del Sur, Av. Arequipa 4861 Miraflores, saby1000@hotmail.com 